\title{
A BELA ADORMECIDA: ESTUDO COM PROFISSIONAIS DO SEXO QUE ATENDEM À CLASSE MÉDIA ALTA E ALTA NA CIDADE DE GOIÂNIA
}

\author{
Concimar da Silva Lopes \\ Ionara Vieira Moura Rabelo \\ Rosely Pereira Barbosa Pimenta \\ Universidade Paulista, Goiás, Brasil
}

\begin{abstract}
RESUMO: Esse estudo propõe-se a fazer uma pesquisa exploratória entre profissionais do sexo que atendem à classe média alta e alta na cidade de Goiânia. Tal proposta justifica-se por Goiânia ter sido apontada como rota do tráfico internacional de mulheres e objetiva investigar quais são as percepções que a profissional do sexo de classe média tem a respeito de si, do seu corpo e de sua profissão. Tenta compreender como estas profissionais relacionam-se com a sua própria sexualidade e suas percepções sobre o tráfico de mulheres. Foram visitadas casas de shows da cidade e entrevistadas quatro profissionais do sexo. As entrevistadas em seus discursos tentam sustentar a posição de mercadoria, sem que isto resulte em maiores conflitos internos. As profissionais do sexo entrevistadas fazem uma cisão entre as identidades de mulher e de prostituta e idealizam situações de tráfico e exploração sexual.
\end{abstract}

PALAVRAS-CHAVE: Prostituição; Psicologia Social; profissionais do sexo; sexualidade.

\section{SLEEPING BEAUTY: RESEARCH INTO SEX PROFESSIONALS WHO SERVE THE UPPER MIDDLE CLASS AND UPPER CLASS IN GOIÂNIA}

ABSTRACT: This study intends to do some exploratory research among sex professionals who serve the upper middle class and upper class in Goiânia, a city in the state of Goiás, Brazil. Such a proposal is justified in reason that Goiânia has been identified as an international corridor for women trafficking. Its objective is to investigate the perceptions that sex professionals, who serve the upper middle class and upper class, have about themselves, their body and their profession. It attempts to understand their relationship with their own sexuality and their perceptions about the trafficking of women. Nightclubs were visited and four sex professionals were interviewed. In their discourse, the interviewees tried to sustain the position of offering a product, avoiding internal conflicts. These sex professionals separate their identities of being woman from that of being prostitutes and idealize situations of trafficking and sexual exploration. KEYWORDS: prostitution; social psychology; sex professionals; sexuality.

A política anti-tráfico, assumida pela Organização das Nações Unidas (ONU) desde 2003, tem produzido um novo foco: desloca-se a atenção da prostituição para a repressão à atividade criminosa internacional. Este reposicionamento termina por configurar um novo discurso que culpabiliza o traficante, que geralmente é reconhecido como pertencente ao país fonte, onde as mulheres são recrutadas. O protocolo da ONU termina por reacender ações etnocêntricas e encoberta a ação de grandes corporações no interior dos países desenvolvidos. Acentua-se o policiamento às migrações sem questionar os problemas estruturais globais que produzem a situação de tráfico de humanos (Kempadoo, 2005).

De acordo com Silva, Blanchette, Pinho, Pinheiro e Leite (2005), a mistura de dados estatísticos provoca um pânico moral entre pesquisadores e população, produzindo generalizações errôneas e falsos consensos. Tais fenômenos terminam por produzir discursos criminalizadores da prostituição.

Desta forma percebe-se um momento em que pesquisadores se debruçam sobre diferentes focos para trabalhar uma mesma temática: por um lado são analisadas as questões de gênero que fomentam o tráfico de mulheres e a prostituição; por outro, são feitas análises críticas sobre o as políticas anti-tráfico enquanto movimento de controle moral. Mas o que fica evidente é o discurso oficial que vincula o tráfico de humanos à prostituição.

A partir do cenário acima, este estudo propõe-se a fazer uma pesquisa exploratória entre profissionais do sexo que atendem à classe média alta e alta na cidade de Goiânia. Tal proposta justifica-se por Goiânia ter sido apontada como rota do tráfico internacional de mulheres pelo estudo realizado por Leal e Leal (2002).

\section{Conceito de tráfico de seres humanos}

Leal e Leal (2002) trabalham com o Protocolo de Palermo para definir tráfico de pessoas como diferentes etapas de um processo que engloba desde o recrutamento, transporte, transferência e o alojamento ou a recolha de pessoas pela ameaça de recursos, à força ou a outras formas de coação, quer sejam por rapto, por fraude, engano e abuso de autoridade. A situação de vulnerabilidade ocorre 
através da oferta ou aceitação de pagamentos, ou de vantagens para obter o consentimento de uma pessoa que tenha autoridade sobre uma outra para fins de exploração.

O conceito de tráfico do Protocolo de Palermo é criticado pelas autoras acima, por não conseguir trabalhar as relações estruturais e subjetivas que alimentam o tráfico. As controvérsias sobre o termo "consentimento" são trabalhadas a partir da categoria "consentimento induzido", que passa a explicar como uma situação de vulnerabilidade social pode propiciar este consentimento que leva à exploração sexual.

A pesquisa organizada por Leal e Leal (2002) identificou que as vítimas brasileiras das redes internacionais de tráfico de seres humanos são, em sua maioria, adultas e saem, principalmente, das cidades litorâneas (Rio de Janeiro, Vitória, Salvador, Recife e Fortaleza). Porém, há registros de casos nos estados de Goiás, São Paulo, Minas Gerais. As pesquisadoras identificaram 241 rotas do tráfico em 20 estados do país, das quais 131 são internacionais, sendo que 33 delas passam pela Região Centro-Oeste. Não foi possível levantar o número total de mulheres submetidas ao tráfico para exploração sexual.

Como o tráfico para fins de exploração sexual de mulheres utiliza-se do tecido social que atua sobre o fenômeno da prostituição, este estudo propõe-se a fazer um breve apanhado sobre este fenômeno e os principais estudos encontrados em periódicos nacionais para depois descrever a metodologia e principais resultados encontrados nesta pesquisa.

\section{Diferentes olhares sobre a prostituição}

Historicamente, a prática da prostituição é tão antiga que se confunde com a história da humanidade. Segundo Torres, Davim e Costa (1999), nenhuma civilização prescindiu dessa atividade.

Quanto ao Brasil, há um discurso oficial que se preocupa com a expansão do mercado do sexo, que seduz, cada vez mais, as jovens a abandonarem suas profissões convencionais para tentar a sorte neste ramo. Por outro lado, existem estudiosos que tentam compreender os significados da prostituição entre profissionais do sexo como, por exemplo, o estudo de Guimarães e Merchán-Hamann (2005), que demonstra que a representação sobre a venda do sexo está se modificando e uma nova categoria está sendo re-significada: a profissional do sexo é aquela que trabalha com a realização de fantasias eróticas.

Atualmente, segundo Castro (1988), o Código Penal Brasileiro relaciona-se com a prostituição de forma ambígua. Ao mesmo tempo em que condena o lenocínio (exploração comercial e incitamento à prostituição), omite a prostituta como pessoa jurídica. Para mudar este panorama, segundo Ortega (2000), iniciou-se em são Paulo, em 1982, um movimento entre as prostitutas que busca trans- formar a prostituição numa atividade profissional que tem seu valor social e direitos como qualquer outra categoria de trabalhadores. Além de direitos trabalhistas, elas reivindicam também que a prostituição seja descriminalizada para que possam legalizar e sindicalizar as suas associações. Atualmente tramita no Congresso Nacional, um projeto de lei do Deputado Fernando Gabeira que propõe exigibilidade de pagamento por serviço de natureza sexual e oficializa o trabalho de profissionais do sexo.

De acordo com Castro (1995), a questão da prostituição perpassa a representação social de "mulher direita" e de "prostituta." Representação esta decorrente da representação dicotômica entre o "mundo de fora" e o "mundo de dentro." A cada qual correspondendo valores sociais, lugares e comportamentos antagônicos que não se interpenetram. A mulher prostituta assume então duas identidades: a de profissional prostituta, que vende o corpo, e a de mulher direita, na qual ela se torna ao sair do ambiente de trabalho. Apesar de este "ser duas" se estruturar com vergonha e culpa, configura-se como uma estratégia de sobrevivência dentro das sociedades contemporâneas, que mantêm sofisticados esquemas ideológicos de controle social e poder.

A respeito da culpa, Castro (1988, p. 127) afirma:

a culpa é utilizada como uma das mais eficazes formas de controle social. A culpa garante a necessidade da ação encoberta, que se fosse desvelada, no caso da prostituição, geraria uma alteridade diante do sistema, no reconhecimento da sexualidade como expressão legítima de afeto e prazer.

Segundo Castro (1988), o corpo sexualizado da prostituta e a possibilidade dela obter prazer com a sua profissão é extremamente ameaçador para a sociedade porque subverte todas as representações ideológicas da sexualidade da mulher, restrita ao papel de procriadora.

A pesquisa de Bruns e Gomes Jr. (1996) contribui para a discussão do fenômeno da prostituição ao analisá-lo a partir de uma perspectiva ontológica. Perspectiva esta baseada na vivência de prostitutas de baixa renda, de uma cidade do interior de São Paulo. Através do método fenomenológico e das categorias EU-TU e EU-ISSO, estes autores procuraram analisar os discursos destas mulheres com a intenção de esclarecer de que forma a prostituta vivencia sua sexualidade, quais sentidos ela atribui à sua vida sexual, de que forma ela se sente como mulher.

Através da análise do discurso das prostitutas, Bruns e Gomes Jr. (1996) constataram que elas se relacionam com seu próprio corpo coisificando-o, estabelecendo-o como uma mercadoria, um ISSO, apenas como um objeto de troca. Há, dessa forma, uma dicotomia entre mente e corpo, o que provoca uma "...ruptura de grandes proporções, fazendo com que ela se torne alheia a si própria..." (Bruns \& Gomes Jr., p. 12). Ao se dividir, a prostituta evita o confronto com seu próprio SER para preservá-lo 
de qualquer tentativa de se envolver numa relação EU-TU consigo mesma e com o outro.

Considerando que os fenômenos da prostituição e tráfico de humanos apresentam-se de forma complexa, esta pesquisa tem por objetivo geral investigar quais são as percepções que a profissional do sexo de classe média têm a respeito de si, do seu corpo e de sua profissão. E, de forma mais específica, objetiva compreender como estas profissionais relacionam-se com a sua própria sexualidade, quais as percepções que têm da sua profissão e como são construídos os discursos sobre o tráfico de mulheres.

Portanto, com a perspectiva de que relações de gênero perpetuam-se nas relações de exploração pelo trabalho, esta pesquisa é relevante no sentido de tentar captar como são elaborados os discursos que justificam a exploração do corpo feminino através da prostituição. Tais mecanismos terminam por regular não só a sexualidade feminina mas também relações de desigualdade social.

Também é importante ressaltar que o universo de significados compartilhados sobre a prostituição feminina termina por servir como mais um instrumento de cooptação de jovens que buscam a ascensão social, e para tal, só conseguem abrir caminho através da venda do próprio corpo. Desta forma é extremamente relevante pesquisar como tais discursos se atualizam no universo da exploração sexual.

\section{Método}

Realizou-se uma pesquisa qualitativa, com autorização do Centro de Estudos e Pesquisas em Psicologia vinculado à Universidade Paulista (UNIP). Este estudo, num primeiro momento, mapeou e visitou algumas "casas de show" e "casas de massagem", direcionadas à clientela de classe média e média alta do município de Goiânia, que noticiam seus serviços através da internet, de jornais escritos de circulação diária e em outdoors espalhados pela cidade. Caracterizam-se como "casas de show" os ambientes que oferecem shows de strip-tease e serviços de acompanhantes, sendo todos estes serviços disponibilizados, preferencialmente, ao público masculino.

Foram visitadas cinco "casas de shows" que atendiam aos critérios acima citados. Numa primeira visita as pesquisadoras se apresentaram aos gerentes das casas noturnas e explicaram o objetivo geral da pesquisa. Todos os gerentes afirmaram que em seus estabelecimentos só trabalhavam dançarinas e modelos e, portanto, não encontraríamos profissionais do sexo para serem entrevistadas.

A partir do segundo contato, as pesquisadoras tiveram que alterar a nomeação para as participantes deste estudo em função da negativa dos gerentes em identificá-las como profissionais do sexo, sendo assim passou-se a procurar por modelos, dançarinas ou acompanhantes. Desde então, as pesquisadoras foram autorizadas a entrar nas "casas de shows", nos horários de funcionamento, para realizar observação do ambiente de trabalho de profissionais do sexo e encontrar trabalhadoras que aceitassem participar voluntariamente deste estudo. Para a observação das casas foi utilizado o diário de campo onde foram anotadas todas as percepções das pesquisadoras.

\section{Descrição dos ambientes}

A casa de massagem pesquisada fica localizada em uma rua de um bairro classe média alta, onde moram famílias tradicionais. Trata-se de um sobrado de três quartos, uma sala de estar modestamente decorada, uma cozinha totalmente convencional. Os clientes as contatam via telefone para combinar o programa, que pode acontecer tanto na casa quanto em qualquer outro local de preferência do cliente. Estes são recepcionados no portão e conduzidos para os quartos, decorados apenas com uma cama de casal simples, uma cadeira comum e cortinas, ali ocorre a consumação da transação comercial. Havia uma média de cinco garotas de programa na casa, revezando-se entre os três quartos. $\mathrm{O}$ preço varia de acordo com a modalidade de sexo combinado. Sexo completo (sexo oral, penetração vaginal e anal) gira em torno de 250,00 reais. Por aproximadamente 500,00 reais elas ficam à disposição do cliente à noite toda.

As "casas de show" que anunciam dançarinas e striptease apresentam configuração física e forma de funcionamento muito parecidas. Durante as incursões, percebeuse que as casas apresentam um palco centralizado com mesas ao centro do salão que são utilizadas pelas garotas que trabalham nas casas. As mesas, que contornam o ambiente, geralmente, encostadas às paredes, são utilizadas pelos clientes. Próximo ao palco localiza-se o bar. Em algumas casas existem camarotes com vidros escurecidos que não permitem visualizar as pessoas no seu interior, em alguns locais os gerentes permitiram que ficássemos nesses camarotes para observação.

Em todas as casas os gerentes afirmaram que o lucro advém apenas do consumo da bebida e do valor pago pelo cliente para entrar na casa. Este valor para entrar variou entre 50 e 75 reais. Com relação ao preço cobrado pelas bebidas notou-se um superfaturamento pois, em comparação aos preços comercializados em bares da cidade, houve a diferença de até $100 \%$ de acréscimo a depender do tipo de bebida escolhida.

Todos os gerentes insistiram em afirmar que, caso os clientes negociassem outros serviços com as mulheres que se encontravam na casa, qualquer programa ocorreria fora do ambiente da casa de shows. Em algumas casas as pesquisadoras tiveram a autorização para visitar todos os ambientes e não foram encontrados quartos nas dependências, mas outras casas só autorizaram incursões nas áreas permitidas aos visitantes. 
Das observações realizadas nos horários de funcionamento é importante relatar que as mulheres utilizavam roupas muito elegantes, nem sempre de caráter chamativo. Em muitos momentos foi possível perceber a utilização de roupas com grifes famosas. A maior parte das mulheres estava com corpos, cabelos, peles e unhas muito bem cuidados. O número de mulheres variou em cada casa noturna com uma média de 50 profissionais por casa, mas este número aumentava nos finais de semana. As profissionais do sexo eram, em sua maioria, novas, parecendo ter entre 20 e 30 anos. Todos os gerentes insistiram em afirmar que não autorizavam a presença de adolescentes com menos de 18 anos de idade.

A rotina de funcionamento foi quase a mesma, no início da noite as mulheres começam a chegar e ficam sentadas conversando nas mesas ao centro do salão. No decorrer da noite, a música vai ficando mais alta e iniciam-se os shows de strip-tease. Os homens que chegam sentam-se nas mesas em torno do salão e observam as mulheres. Em algumas casas, os garçons são solicitados a chamar as mulheres escolhidas para que se dirijam até as mesas dos clientes. Em outras, os próprios clientes se deslocam até o centro do salão para conversarem com as escolhidas. As mulheres também se deslocam até as mesas por conta própria para dançar e conversar com os clientes.

As mulheres, com quem conversamos informalmente durante estas visitas, contaram que observam a bebida que está sobre a mesa para identificar clientes que estão dispostos a gastar mais. Efetivamente, em alguns dias, pudemos perceber que nas mesas em que só havia garrafas de cerveja os clientes tinham mais dificuldade em negociar uma acompanhante. A negociação ocorre na mesa e quando é feito o acordo sobre o programa o casal sai da casa de show, e neste momento o cliente tem que pagar para o proprietário o valor do ingresso da mulher.

As profissionais que fazem os shows de strip-tease afirmam que cobram valores mais caros para seus programas, algumas também nos mostraram algumas revistas de circulação local e nacional onde apareceram fotos delas, e também afirmaram cobrar mais caro por seus serviços.

\section{Participantes}

Foram entrevistadas quatro mulheres entre 18 e 30 anos, profissionais do sexo, solteiras, escolaridade superior incompleto, com renda mensal entre 3000,00 e 8000,00 reais, que anunciam seus serviços em classificados de jornais de circulação diária na cidade de Goiânia ou atendem em casas noturnas de strip-tease e casas de massagem.

\section{Procedimentos}

Após algumas noites de observação, conversamos com várias mulheres e convidamos as mesmas a participarem de entrevistas. Àquelas que voluntariamente se dispuseram a participar do estudo foi apresentado e assinado o
Termo de Consentimento Livre e Esclarecido. As entrevistas ocorreram nos locais escolhidos pelas próprias participantes, sendo assim algumas foram nas "casas de shows" e outras escolheram conversar fora do horário de trabalho em locais onde atendem aos clientes. A respeito da temática tráfico de mulheres, as entrevistadas não aceitaram a gravação deste tópico, mas permitiram a anotação em diário de campo sobre algumas histórias que souberam contar sobre o tema. Todos os outros tópicos da entrevista puderam ser gravados, em seguida as entrevistas foram transcritas e posteriormente analisadas a partir de categorias temáticas. Estas categorias foram encontradas através da técnica de triangualação proposta por Minayo (1999), desta forma, utilizou-se o diário de campo juntamente com a transcrição das entrevistas para eleger as categorias que conseguiram expressar elementos com características comuns.

Ocorreram três encontros com cada sujeito, em locais e horários pré-determinados pelas entrevistadas. As entrevistas foram realizadas entre julho e outubro de 2005.

\section{Discussão dos Resultados}

Todas as entrevistas foram analisadas em profundidade a partir da construção do discurso de cada profissional do sexo. Tentou-se aglutinar categorias temáticas que nortearam seu discurso e encontrou-se oito categorias que são discutidas a seguir.

\section{O Ter justifica o Ser}

De acordo com as entrevistadas, os fins justificam os meios, já que, através do dinheiro ganho na prostituição, é possível adquirir respeito, amigos, família e tudo mais que necessitam para viver dignamente. Não importa a profissão, o que importa é o dinheiro advindo dela, que lhes irá possibilitar acesso a um padrão de vida de classe média alta com o qual sonham e, dessa forma, serem aceitas e bem tratadas pela sociedade.

"Não conheço pobre respeitada. Respeito é usar óculos Chanel e bolsa Louis Vuitton" (Participante 1).

"O que mais me importa é o quanto eu consigo ganhar com esta profissão” (Participante 3).

\section{O conflito é social}

Segundo os seus relatos, elas não vivenciam nenhum conflito psicológico por exercerem a profissão de prostituta. Se há algum conflito, na realidade, é externo a elas, é social, pertence ao cliente, conseqüentemente, à sociedade, que as procura por estar em conflito consigo mesma, em relação às questões sexuais. Argumentam que é somente ali com elas que o homem pode liberar-se, mudar de identidade.

\footnotetext{
"Meu cliente é juiz. Quando chega aqui se veste de mulher e pede para eu usar vibrador nele" (Participante 2).
} 
“...Às vezes eles não vêm em busca do sexo, vêm em busca da companhia” (Participante 2).

Elas relatam ainda não se incomodar de serem alvos de discriminação por parte da sociedade. Porém, demonstram uma certa ironia quando observam que a sociedade diferencia entre a mulher que vende seu corpo e a mulher que o usa de acordo com seu desejo. A mulher que vende o corpo não presta, já a mulher que tem uma vida sexual ativa, apenas não tem juízo, falta-lhe orientação.

"Acho que eu não fico constrangida não, mas acho que a sociedade é muito falsa. Falam das prostitutas mas todos vêm procurá-las" (Participante 3).

"Mulher que se vende não presta, a que dá de graça, coitada, é sem juízo” (Participante 4).

Em seus discursos, as entrevistadas demonstram recusar o papel de vítimas dos homens e das circunstâncias das suas próprias vidas. Embora tenham sido levadas a se prostituir por contingências adversas, isto não significa que não tiveram consciência das suas escolhas, feitas não sem antes ponderar quais seriam as perdas e os ganhos. Percebe-se que essa opção, ser uma profissional do sexo, possibilitou-lhes o acesso a bens e a um estilo de vida que de outra forma não seria possível, o que as faz sentir-se dignas, vitoriosas, donas de si mesmas e do seu destino.

"Eu escolhi esta profissão porque daqui eu consigo as coisas mais rápidas, eles pagam" (Participante 3 ).

As entrevistadas também procuram justificar e legitimar a sua profissão, dentro de uma sociedade capitalista e individualista, ao se auto-proclamarem úteis à sociedade uma vez que suprem a carência de companhia e atenção de homens solitários e depressivos, gerados por este tipo de sociedade. Em alguns de seus relatos, elas dizem fazer parte da profissão escutar e amparar os homens que estão em busca de companhia e atenção, nesse sentido, elas chegam a afirmar que são "quase psicólogas."

“...você passa a ser quase que um psicólogo porque ouve tantos os problemas dos outros que, quando você deita, você vai pensar no seu, né?" (Participante 3).

"Alguns só querem companhia, tipo falar mesmo, quer ser ouvido" (Participante 3).

\section{O corpo: instrumento de troca}

Uma das entrevistadas relata que a sua profissão influencia beneficamente na questão do envelhecimento por lhe proporcionar meios financeiros para tratamentos que irão preservar ao máximo a sua juventude e, conseqüentemente, sua permanência neste exigente mercado de trabalho, que demanda moças com boa aparência e jovens. Para ela, o fato de não dormir à noite não afeta em nada no processo de envelhecimento já que ela pode compensar o sono perdido durante o dia.
"O ser [prostituta] não envelhece, o que envelhece é a bebida e a falta de dinheiro para cuidar do corpo. Se tenho dinheiro não envelheço, não existe mulher feia, só mulher sem dinheiro” (Participante 1).

"Eu sou uma jóia preciosa que fica exposta em uma vitrine e, a qualquer momento, vai chegar um cliente que vai pagar muito por mim” (Participante 1).

Vê-se, então, que as entrevistadas consideram o seu corpo como instrumento de trabalho e o tratam como tal, através de cuidados estéticos e de saúde. O corpo para elas é objeto, verdadeira arma de sedução, que lhes propicia alcançar seus objetivos financeiros. "Você tem que atendê-lo como se fosse, como se esti-
vesse vendendo um produto" (Participante 2).

\section{Uma questão de identidade}

Pela fala das entrevistadas, torna-se evidente que a identidade delas como profissional está atrelada ao nível sócio-econômico dos clientes que elas atendem. Quanto maior o status destes, maior será o status delas. Por isso, elas só atendem clientes de classes sócio-econômicas mais altas, podendo assim cobrar mais caro pelos seus serviços. De acordo com estas profissionais, elas dispensam clientes pelo carro que usam, pois não será bom para elas serem vistas com um cliente que não possua uma posição social.

"Só atendo gente da alta, jornalista, deputado, senador, só quem paga bem. Pobre não tem dinheiro para pagar meu preço” (Participante 1).

"Não saio com um cara que chega em uma furreca" (Participante 4).

Os relatos revelam também que elas sofrem conflitos em relação às suas identidades apesar de dizerem haver uma divisão bem demarcada em suas mentes entre a profissional prostituta e a pessoa (mulher, mãe, amiga, namorada, etc.) que, na verdade, são fora do ambiente de trabalho. Porém, o que se percebe é que essas identidades confundem-se e, em algum momento, fundem-se em uma única, chegando assim ao ápice do conflito: momento em que elas já não distinguem mais os papéis de dentro e fora do trabalho, como consequiência, já não sabem mais quem são.

"Me pego sendo J... dentro de casa ao lado dos meus filhos, sou tão dura quanto ela, acho que ela tem muito de mim, ou eu dela. Sabe, aprendi muito com ela” (Participante 1).

"Eu costumo falar que a gente assume muita máscara, né? Então aqui eu me mascaro como a L... e lá eu assumo a minha identidade mesmo, que é uma pessoa muito pacata mesmo...” (Participante 2).

O conflito é que às vezes perde um pouco porque, às vezes, eu estou na faculdade e eu tenho uma colega com o mesmo nome meu [nome usado como profissional do sexo], L... E, às vezes, chamam, na chamada mesmo, 'L...', e eu quase falei 'eu'. Então, é muito 
complicado isso, às vezes você vai perdendo (Participante 2).

"Sou puta mas sou mãe, isso não dá para separar não, acho que isso é impossível” (Participante 3).

\section{De vez em quando bate a solidão}

De acordo com os relatos, esta é uma profissão em que a profissional não tem amigas dentro do campo de trabalho, pois há uma concorrência árdua entre elas. As colegas de trabalho não são pessoas confiáveis e uma maior intimidade poderá virar uma arma contra elas mesmas. Por isso, elas se isolam dentro de seus próprios mundos, traçam metas a cumprir e procuram não pensar no que está a sua volta. Esta reflexão só ocorre quando, ao dormir, encontram-se sozinhas e isoladas.

"Eu costumo dizer que você, apesar de ter encontrado tantas pessoas naquele dia, às vezes, eu me sinto só mesmo, eu acho que vem a solidão" (Participante 2).

"Nesse mundo da prostituição, você não pode ter tantos amigos. São amigos mas entre aspas assim, às vezes não dá pra confiar muito" (Participante 2).

\section{Ambigüidade na relação com o dinheiro}

Segundo as entrevistadas, o dinheiro que conseguem com seu trabalho é um dinheiro fácil, mas não tão fácil assim. É fácil porque, em pouco tempo, elas ganham um valor que a maioria das pessoas levaria meses para conseguir. É difícil porque têm que realizar os desejos sexuais de pessoas estranhas e, para isto, às vezes, têm que se violentar em seus atos. A ambigüidade em relação ao dinheiro perpassa suas relações profissionais. Percebe-se isto em algumas falas das entrevistadas, que se dizem constrangidas no momento de cobrar pelos seus serviços, mesmo havendo um contrato verbal previamente estabelecido a respeito do valor que será cobrado.

"É um dinheiro fácil, mas não tão fácil assim porque me violento" (Participante 1).

O fato de pagar é o que incomoda muito. Então acho que é o conflito da profissão e o eu mesmo... 'Nossa ele tá me pagando pra fazer isso', acho que é esse conflito теsтo. $\mathrm{O}$ seu eи e profissão (Participante 2).

"Uma das dificuldades que eu tive pra entrar na profissão é pedir dinheiro, falar 'olha passa o dinheiro, gatinho e tal'. Isso me incomodou muito. $O$ dinheiro me incomodou muito" (Participante 2).

"Sabe não é um dinheiro fácil, mas vem rápido. Acho que é por isso que a gente gasta rápido, até que eu seguro, mas poderia guarda mais, também tenho que investir em mim, você sabe, né?" (Participante 3).

\section{O que seria do casamento sem as prostitutas}

Em seus relatos, a profissional do sexo considera-se necessária para a manutenção da moralidade e da institui- ção familiar. Seus clientes dizem não conseguir ficar por vários anos com a mesma parceira sexual, necessitando assim manter relações sexuais com outras mulheres. Para elas, é nesse ponto que elas são benéficas, pois suprem esta demanda dos homens sem que eles tenham que manter vínculos afetivos ou de outra ordem com elas, podendo assim retornar ao lar sem maiores conseqüências.

"Atendo vários homens casados, ainda bem que eu existo porque senão eles iriam procurar as amigas das esposas para namorar e transar, aí o casamento acaba” (Participante 1).

"Não sei o que seria das casadas sem as putas, elas iam perder seus maridos" (Participante 3).

"Sorte das mulheres casadas que existe as putas, só transamos com os maridos, pelo dinheiro, não há afeto" (Participante 4).

\section{Tráfico como um Conto de Fadas}

Nos relatos que não puderam ser gravados foi possível perceber que as profissionais do sexo só contam histórias daquelas profissionais que foram ao exterior e conseguiram sair do que denominam "círculo", quando rompem com os agenciadores e conseguem trabalhar por conta própria, ganhando muito dinheiro antes de retornar ao Brasil, ou mesmo casando-se com um estrangeiro. Tais histórias sobrepõem-se àquelas onde o "círculo" não é facilmente rompido. As escolhas das histórias com finais felizes em oposição às vivenciadas com sofrimento apontam como a idealização norteia o discurso das participantes.

\section{Discussão}

Castro (1988) chama a atenção para uma concepção moralista e ambígua da prostituição. Vista, tradicionalmente, como um mal necessário para a preservação da sociedade e da família. Tal ponto de vista pôde ser verificado na fala das entrevistadas, que se consideram importantes para a preservação da instituição do casamento porque, segundo elas, o homem não consegue manter o desejo sexual pela mesma parceira ao longo dos anos, necessitando assim de estímulos extra-conjugais para manter acesa a sua sexualidade e, ao mesmo tempo, manter-se "fiel" a seus votos matrimoniais. De acordo com elas, um homem, ao procurar seus serviços, pode ter tudo aquilo que anseia sexualmente sem o inconveniente de ter que manter relações de compromisso com elas, podendo então livremente voltar para o lar e cumprir o seu papel dentro dele.

Em sua contribuição para o tema, Gomes (1994) argumenta que a prostituição leva à "coisificação" das mulheres, cujos corpos são transformadas em objetos de venda que podem e devem ser escolhidos e comprados como uma mercadoria. A veracidade desta afirmação de Gomes (1994) pôde ser constatada pela fala de uma das entrevis- 
tadas que se compara a uma jóia exposta que, a qualquer momento, será escolhida e muito bem paga por ser valiosa e bela. Para sustentar a posição de mercadoria, sem que isto resulte em maiores conflitos internos, as entrevistadas fazem uma cisão entre as identidades de mulher e de prostituta.

Pelos seus discursos, observou-se que, para se salvarem de conflitos internos, recorrem ao papel de prostituta, sustentando, para si mesmas e para os outros, que quem está à venda é a profissional prostituta que, em seu trabalho, não tem emoção ou sentimentos, sendo estes somente permitidos às pessoas que verdadeiramente são, mas que só têm existência fora do ambiente de trabalho. Apesar de afirmarem com veemência esta idéia, percebeu-se que esta cisão não é tão bem-sucedida quanto elas querem crer e, por mais que tentem negar, em algum momento de suas vidas, essas duas identidades fundem-se em uma única, fazendo com que elas tenham que se deparar com dolorosos conflitos psicológicos que vêm à tona, como a solidão e o conflito de identidade. Tal conflito vem ao encontro do estudo de Castro (1995) que trabalha a dicotomia mulher direita e prostituta.

Pelos seus relatos, constatou-se também que estas mulheres são vítimas de uma sociedade capitalista que as estimula constantemente a terem um corpo perfeito, porém sem mente, que sirva de objeto de exploração daqueles que, por ele, possam pagar. Por outro lado, elas se dizem dispostas a encarar essa vida porque é através dela que obtêm acesso a luxos que, de outra forma, jamais conseguiriam.

Tornou-se evidente, pelas suas falas, o quanto estão imersas numa ideologia capitalista. Regidas pelos ditames de uma sociedade altamente consumista em que o grande prazer é ter e não ser. Neste aspecto percebe-se valores que também são debatidos por Liborio (2004) quando fala do desejo da inclusão social por meio do consumo, desta forma, jovens se prostituem em prol da manutenção não só da sobrevivência, mas principalmente para manter seu status social.

A partir desta possibilidade de existência, "o ter", as entrevistadas passam a elaborar as possibilidades de ascensão social que a prostituição, seja aqui ou no exterior pode propiciar. A construção e manutenção de discursos idealizados são a principal fonte de cooptação de jovens para entrarem na rota do tráfico, porém, foi interessante perceber que tal discurso é freqüente mesmo entre profissionais que já foram exploradas no exterior e voltaram para o Brasil após fugir do "círculo", como foi o caso de duas participantes deste estudo. Tal resultado aponta para um novo perfil de aliciadores, onde os discursos compartilhados por estas profissionais terminam por alimentar o tráfico de mulheres. Este pefil não havia sido detectado no estudo de Leal e Leal (2002) que até então localizava que eram os homens os principais aliciadores do tráficos ou mesmo mulheres, no caso vizinhas, parentes e amigas.

As participantes ao se referirem à possibilidade de trabalho no exterior, parecem reproduzir o conto da bela adormecida a espera do príncipe encantado. Escolhem sempre falar das "princesas" salvas do sono eterno pelo beijo de um príncipe. Mais interessante torna-se este fato se nos lembrarmos das análises de historiadores que atribuem o início deste conto a uma história contada entre camponeses, em que uma princesa era violentada sexualmente por um príncipe e só foi acordada pelas mordidas de seus filhos que nasceram após esta violência. Será que a vivência de relações desiguais e violentas não são o bastante para acordar tais mulheres do sono e do sonho no exterior? Será que recontam histórias para novamente sonharem com uma possibilidade quase milagrosa de libertação, quando na verdade se submetem a novos cárceres?

Apesar de toda essa realidade que as vitima, observouse que as profissionais do sexo não aceitam, de forma alguma, o papel de vítimas destinado a elas. Pelo contrário, elas julgam-se possuidoras de um poder, privilégio de poucas, que é o poder de ter o homem que desejarem por serem verdadeiras armas de sedução. Justamente por isso, sentem-se superiores em relação às mulheres ditas "normais", que não possuem tal poder sobre os homens. As participantes deste estudo não se sentem vitimizadas, pelo contrário, transgridem a moral social que nega a sexualidade do corpo prostituído, tal fato é apontado por Castro (1988) que avalia como a prostituição subverte todas as representações ideológicas sobre a sexualidade feminina, esta representação só aceita os papéis de mulher "direita" e procriadora.

Pelos seus discursos, constatou-se que as entrevistadas encontram-se alienadas por uma ideologia dominante, machista e capitalista, embora não percebam tal processo de alienação ocorrendo com elas. Em suas falas e vivências subjetivas, elas representam a ideologia capitalista, que propaga a lei do individualismo, da liberdade de escolha e do obter sucesso não importa de que forma. Percebeu-se esta representação ocorrer quando elas se gabam de serem mulheres livres com pleno poder e consciência de si para fazer suas escolhas e dirigir suas vidas. Entretanto, estas mulheres, que se dizem livres, não percebem que reproduzem, ao se colocarem no lugar de mercadorias, a dinâmica cruel da ideologia dominante, que se organiza através dos papéis do dominador e do dominado, do explorador e do explorado. Nesta dinâmica, que não as favorece de forma alguma, ocultado pelo véu de sua suposta liberdade de escolha, elas assumem, mesmo sem saber, o papel menor de exploradas e dominadas.

\section{Considerações Finais}

Por permitir uma compreensão mais acurada dos discursos produzidos no universo vivenciado por profissio- 
nais do sexo, pode-se considerar que os objetivos propostos pela presente pesquisa foram alcançados. Apesar de não ser exaustivo, o conhecimento gerado por esta pesquisa pode ser relevante tanto para psicólogos clínicos quanto para profissionais da psicologia social que lidam com essa população.

É importante ressaltar que o conhecimento sobre os significados compartilhados entre profissionais do sexo pode auxiliar as políticas públicas que tentam trabalhar combatendo o tráfico de mulheres. Os discursos pesquisados por este trabalho apontam que não só agenciadores, mas principalmente, as próprias profissionais constroem idealizações sobre o trabalho no exterior e fomentam este comércio.

Relações de exploração são re-significadas pelas profissionais que apontam que trabalho mal pago é que configura escravidão, tal categoria pode auxiliar na compreensão de novas fronteiras onde profissionais do sexo tentam se legitimar exatamente pela falta de outras oportunidades de trabalho rentáveis. Novamente o capitalismo revela sua face coisificadora das relações cotidianas e transforma corpos em ferramentas, bem como existências transformamse em produtos e serviços.

\section{Referências}

Bruns, M. A. de T., \& Gomes, O. P., Jr. (1996). Prostituição: O discurso de quem se vende e o silêncio de seu comprador. Jornal Brasileiro de DST, Rio de Janeiro, 8(4), 4-13. Retirado em 07 mar. 2005, da Base de dados LILACS (Literatura Latino-Americana e do Caribe em Ciências da Saúde).

Castro, R. V. (1988). Mulheres más. Psicologia Clínica, 3(3), 121129. Retirado em 27 fev. 2005, da Base de dados INDEXPSI (Index Psi Periódicos).

Castro, R. V. (1995). Representações sociais da prostituição na cidade do Rio de Janeiro. In M. J. Spink et al. (Ed.), O conhecimento no cotidiano: As representações sociais na perspectiva da Psicologia Social (pp.149-187). São Paulo, SP: Brasiliense.

Gomes, R. (1994). Prostituição infantil: Uma questão de saúde pública. Cadernos de Saúde Pública, 10(1), 58-66. Retirado em 27 fev. 2005, da Base de dados SciELO (Scientific Electronic Library Online).

Guimarães, K., \& Merchán-Hamann, E. (2005). Comercializando fantasias: A representação social da prostituição, dilemas da profissão e a construção da cidadania. Revista Estudos Feministas, Florianópolis, 13(3), 525-544.

Kempadoo, K. (2005). Mudando o debate sobre o tráfico de mulheres. Caderno Pagu, 25, 55-78.

Leal, M. L., \& Leal, M. F. P. (Eds.). (2002). Pesquisa sobre tráfico de mulheres, crianças e adolescentes para fins de exploração sexual comercial (PESTRAF: Relatório Nacional-Brasil). Brasília, DF: CECRIA.

Liborio, R. M. C. (2004). Exploração sexual comercial infanto-juvenil: Categorias explicativas e políticas de enfrentamento. In R. M. C Liborio \& S. M. G. Sousa. Exploração sexual de crianças e adolescentes no Brasil: Reflexões teóricas, relatos de pesquisas e interveções psicossociais (pp. 19-50). São Paulo, SP: Casa do Psicólogo.

Minayo, M. C. S. (1999). O desafio do conhecimento: Pesquisa qualitativa em saúde. São Paulo, SP: HUCITEC.

Ortega, C. de A. (2000). Prostituição e trabalho: Um estudo sobre a visão de mulheres de programa. Aprimoramento em Saúde Coletiva: Reflexões, São Paulo, 45-50, Retirado em 27 fev. 2005, da Base de dados LILACS.

Silva, A. P., Blanchette, T., Pinho, A. M. M., Pinheiro, B., \& Leite, G. S. (2005). Prostitutas, "traficadas" e pânicos morais: Uma análise da produção de fatos em pesquisas sobre o "tráfico de seres humanos". Caderno Pagu, 25, 153-184.

Torres, G. de V., Davim, R. M. B., \& Costa, T. N. A. da. (1999). Prostituição: Causas e perspectivas de futuro em um grupo de jovens. Revista Latino-Americana de Enfermagem, 7(3), 9-15. Retirado em 03 mar. 2005, da Base de dados LILACS.

Concimar da Silva Lopes é graduada em Letras habilitação em Língua Portuguesa pela Universidade Federal de Goiás. Graduanda em Psicologia pela Universidade Paulista, Goiás.

concisl@hotmail.com

Ionara Vieira Moura Rabelo é psicóloga, mestre em Psicologia pela Universidade Católica de Goiás, professora adjunta do Instituto de Ciências Humanas da Universidade Paulista (UNIP - Campus Goiânia), psicóloga do CAPS Beija-flor da Secretaria Municipal de Saúde de Goiânia. Endereço para correspondência: Universidade Paulista - BR 153, Km 503, área 1/5, Bairro Fazenda Botafogo. Goiânia - GO, CEP: 74845-090. ionaravmr@yahoo.com.br

Rosely Pereira Barbosa Pimenta é graduanda em Psicologia pela Universidade Paulista, Goiás. roselypimenta@hotmail.com

\section{A Bela Adormecida: estudo sobre prostituição e tráfico de mulheres}

Concimar da Silva Lopes, Ionara Vieira Moura Rabelo

e Rosely Pereira Barbosa Pimenta

Recebido: 10/07/2006

$1^{a}$ revisão: 06/11/2006

Aceite final: 28/11/2006 